\title{
st \\ A tradução química de experimentos alquímicos envolvendo água régia em Robert Boyle \\ Kleber Cecon
}

\begin{abstract}
$\ddot{\sim}$
RESUMO

Recentemente, alguns acadêmicos têm demonstrado que a tradução química pode auxiliar o trabalho histórico. O objetivo deste trabalho é traduzir alguns experimentos alquímicos de Robert Boyle para a química contemporânea, particularmente, aqueles que envolvem a água régia. A maior parte desses experimentos tem relação com o mecanicismo boyleano, com receitas de produção de compostos e com a padronização de procedimentos químicos. Muitos deles envolvem descrições precisas de propriedades, tais como o ponto de fusão, a mudança de gosto, a liberação de som e bolhas, a corrosão etc., que podem ser usadas como ferramentas de rastreamento para uma tradução à notação química atual.
\end{abstract}

Palavras- $\mathrm{CHAVE} \bullet$ Boyle. Experimentos alquímicos. Tradução química. Água régia. História da química. História da ciência.

\section{INTRODUÇÃO}

A expressão "tradução química", tal como usada neste artigo, compreende a ideia de traduzir a descrição de um experimento químico/alquímico de um texto antigo para a linguagem e notações da química contemporânea. Houve recentemente um crescente interesse nesse tipo de atividade para descodificar passagens envolvendo reações químicas em documentos históricos (cf. Principe, 2000; Newman \& Principe, 2002). Apesar de problemas referentes ao contexto histórico e cultural (cf. Newman \& Principe, 2004, p. xii), termos em código (cf. Principe, 1992, p. 63) e a presença de impurezas nos reagentes antigos (cf. Principe, 1987, p. 21), ela se tem mostrado possível, assentando-se em desenvolvimentos da filosofia da linguagem (cf. Kiтcher, 1978, p. 519; 1982, p. 689), e mostra-se útil para a compreensão de procedimentos experimentais na história da química (cf. Usselman et al., 2008, p.106; Kronberg et al., 1984, p. 295; Principe, 1998, p. 161). 
Quando se realiza a identificação da água forte com o ácido nítrico, por exemplo, esse não é o ácido padronizado que se usa atualmente nos laboratórios. Os materiais utilizados em épocas passadas possuem concentrações, impurezas e eventuais peculiaridades praticamente impossíveis de precisar; por isso, o que se faz neste artigo, quando se identifica a água forte com o ácido nítrico, é estabelecer que existe uma quantidade tal desse ácido na citada água que explica suas propriedades químicas e físicas descritas nos textos históricos analisados. A água forte não é, nem nunca será, o ácido nítrico padronizado de hoje, mas o eventual maior ou menor grau de pureza, assim como a presença de outras substâncias, não parece ser um problema para identificála, pelo menos nas reações que são analisadas neste artigo. O que se propõe são algumas poucas reações, envolvendo certa temática, as quais são passíveis de uma tradução e que ela procede nesses casos específicos.

Outra questão digna de nota é que a análise de tradução é realizada tendo em vista o referente, ou seja, ela é focada no material e não nos conceitos ou no sentido dos termos. Isso pode ser encontrado com mais detalhes em argumentos dados nas já citadas referências de filosofia da linguagem (cf. Kitcher, 1978, p. 519; 1982, p. 689), as quais não pretendo reproduzir detalhadamente aqui. Quando chamo de $\mathrm{NaCl}$ o que antes era chamado de sal marinho, é porque estou fazendo referência ao material majoritário presente naqueles cristais brancos obtidos da evaporação da água do mar. Obviamente não estou supondo que autores antigos, de 350 anos atrás, pensavam os processos de transformação da matéria utilizando essa nomenclatura (o que seria ridículo), muito menos que eles possuíam todos os conceitos idênticos aos atuais a respeito dele, mas ambas, as notações $\mathrm{NaCl}$ e o nome "sal marinho", apontam para a mesma referência no mundo. Chamar isso de tradução não implica necessariamente que um símbolo único corresponda a outro; o autor não precisa de símbolos para ser traduzido, mas sim de dois termos indicando o mesmo referencial no mundo. A notação contemporânea tem um motivo, que é estabelecer uma comunicação padronizada dos conceitos atuais; ora, este artigo é escrito para ser lido por químicos de hoje; logo, a notação serve como chave de leitura e informação a respeito do material e processos descritos no texto.

É importante salientar que duas objeções podem ser feitas com relação ao uso da referência na tradução química. A primeira é que isso não é objeto da história da ciência. George Canguilhem em seu texto sobre o objeto da história da ciência defende que "o objeto na história das ciências nada tem em comum com o objeto da ciência" (Canguilhem, 1979, p. 17). Portanto, a tradução química, ao deslocar o foco do sentido e concentrando-se apenas na referência, estaria igualando o objeto da história da ciência com o objeto da ciência. Na verdade, a atividade de tradução química não tem a pretensão de ser objeto da história da química, mas simplesmente uma ferramenta 
dela. No momento inicial em que são coletadas as fontes primárias e analisados os documentos, entendendo a linguagem, o ambiente e os conceitos do autor, o que se faz é efetivamente história da química. A partir do momento que o foco é dado na referência, e não mais no sentido como antes, tentando entender e descrever com uma nova linguagem e conceitos aquele fenômeno descrito, o que se faz não é mais história da química, mas algo dentro da ciência química. $\mathrm{O}$ fato, porém, dessas duas atividades possuírem objetos de estudo que, acredito, sejam realmente distintos, não impede ambas de agirem em conjunto para um mesmo fim. A tradução apresentada neste artigo não tem como propósito ser objeto próprio da história da ciência, nem se compromete em igualar o objeto da história da química com o da química, mas apenas servir como ferramenta visando apresentar uma chave de leitura dos processos descritos por Boyle para o leitor contemporâneo.

A segunda objeção que pode ser apresentada é de que esse foco forte na referência implicaria em uma relação direta com um mundo objetivo e com a "coisa em si", acarretando um comprometimento com toda a carga epistemológica dessa suposição. Isso não procede, visto que não é necessário que a referência da tradução seja algo em si mesmo ou algo objetivo, basta que exista um fenômeno que seja compartilhado igualmente pelas duas partes (comunidades) envolvidas na tradução. O comprometimento que existe é que haja algo compartilhado igualmente. Caso isso não ocorra, não existe fundamento para a tradução, pois não existiria fator comum que os conectasse. Considerando essa possibilidade, até mesmo Thomas Kuhn (1922-1996), que foi quem introduziu na filosofia da ciência o conceito de incomensurabilidade, ${ }^{\mathbf{1}}$ concorda que é possível estabelecer um processo de tradução utilizando-se de uma referência comum. Quando confrontado com exemplos de tradução de termos da química do flogístico do século XVIII usando termos da química do século xx através de processos referenciais, Kuhn concorda que isso é uma crítica contundente, pelo menos para a noção mais ampla de incomensurabilidade.

A teoria do flogístico tem fornecido um de meus exemplos-padrão, e Philip Kitcher utilizou-o como base para a crítica contundente da noção ampla de incomensurabilidade (...). Kitcher argumenta, penso que com sucesso, que a linguagem da química do século xx pode ser usada para identificar os referentes dos termos e expressões da química do século xviıI, pelo menos na medida em que esses termos e

\footnotetext{
1 Em 1962, Thomas Kuhn e Paul Feyerabend (1924-1994) introduziram o conceito de incomensurabilidade. O nome vem de uma analogia da matemática, já que os lados de um quadrado são incomensuráveis com a diagonal do mesmo. Esse termo é usado para designar a ideia de ausência de um fator comum ou, no caso mais específico, de uma linguagem comum entre duas "ciências normais" e que, portanto, não seria possível explicar uma ciência através de outra, visto que não existiriam termos, conceitos, ou paradigmas comuns a elas.
} 
expressões realmente se refiram a alguma coisa (...). Não tenho dúvida de que historiadores lidando com velhos textos científicos possam e devam usar a linguagem moderna para identificar os referentes de termos obsoletos (...). Além disso, a introdução de uma terminologia moderna torna possível explicar por que e em que áreas as teorias velhas foram bem sucedidas (Kuhn, 2006, p. 55-6, grifo nosso).

Dadas essas considerações introdutórias a respeito da atividade da tradução química, parece razoável dizer que ela pode suscitar discussões e que possui um espectro de atuação bem limitado, mas ainda assim ela é possível. É dentro desse escopo possível que se dão os exemplos citados neste artigo.

\section{1 Овјетivo}

O objetivo do artigo é realizar a tradução química de alguns experimentos encontrados nos textos de Robert Boyle (1623-1691), que se referem à água régia. A escolha pelos textos de Boyle deve-se ao fato de que vários de seus experimentos são passíveis de tradução, como já constatado anteriormente (cf. Cecon, 2011a).

Alguns autores colocam Boyle, entre outros químicos, dentro da revolução científica do século xviı (cf. Debus, 1998, p. 66). Hoje, ele é conhecido como um dos grandes nomes da filosofia da natureza do século xvıı, principalmente devido aos seus trabalhos químicos em laboratório, que eram muito próximos ao que chamamos de química experimental (cf. Newman \& Principe, 2002). Isso é razoável já que o principal processo pelo qual Boyle altera a textura dos corpos é através de experimentos químicos.

Antes que se objete sobre a identificação do trabalho de Boyle com a química ou a alquimia, é importante frisar que diversos trabalhos apontam que esses termos eram usados como sinônimos no século xviı (cf. Newman \& Principe, 1998) e que a separação dessas práticas, conferindo um tom pejorativo à alquimia, só ocorreu posteriormente (cf. Newman \& Principe, 2001, cap. 8). Influenciados por essa concepção, os historiadores selecionaram o material biográfico de Boyle de forma a evitar as conexões alquímicas (cf. Hunter, 1994). Hoje sabemos que a química de Boyle incluía a busca da pedra filosofal, do elixir da longa vida e do alkahest (solvente universal). Um experimento presente em diversas obras de Boyle foi a obtenção de água régia, e é ela o objeto de tradução química deste artigo. 
A tradução química de eXPerimentos Alquímicos envolvendo ÁGUa régia em Robert Boyle

\section{A filosofia mecânica de Robert Boyle}

A teoria da matéria de Boyle é complexa e sua exposição detalhada foge completamente ao objetivo deste artigo, porém, segue-se uma breve exposição de seus principais pontos, visando elucidar algumas questões que serão discutidas no decorrer deste artigo. Os tópicos aqui expostos podem ser encontrados na obra em que Boyle os discute com mais detalhes, que se chama Origem das formas e das qualidades (The origin of forms and qualities), inicialmente publicada entre 1666 e 1667.

Boyle baseava sua hipótese corpuscular na existência de uma matéria universal, comum a todos os corpos, que é substância extensa, divisível e impenetrável (cf. Boyle, 2000 , v. 5, p. 305). Essa matéria está dividida em pequeníssimos corpos que, apesar de serem divisíveis pela mente humana ou pela onipotência de Deus, devido à sua pequenez e solidez, praticamente nunca são divididos na natureza e, nesse sentido, podem ser chamados de mínima ou prima naturalia (cf. Boyle, 2000, v. 5, p. 325-6). Essas pequenas partículas primárias da natureza (que serão aqui chamadas simplesmente de corpúsculos) possuem movimento, que não é essencialmente inerente a elas. Deus estabeleceu as leis do movimento entre os corpos e guiou os primeiros movimentos das pequenas partes da matéria, reunindo-as de maneira a compor o mundo (cf. Boyle, 2000 , v. 5, p. 306). Logo, os dois maiores e mais universais princípios dos corpos são a matéria e o movimento.

A matéria, por ser extensa, possui atributos acidentais inseparáveis, como tamanho e forma (cf. Boyle, 2000, v. 5, p. 3o ). Essas partículas pequenas com diversos tamanhos e formas agrupam-se em agregados ou concreções primárias estáveis (que serão aqui chamados simplesmente de agregados); porém, sua adesão é tão intensa e estrita que cada uma dessas pequenas concreções primárias, ou agregados de partículas, raramente são dissolvidas ou quebradas, mas permanecem inteiras em uma grande variedade de corpos sensíveis, sob diversas formas, apesar de serem potencialmente divisíveis nos corpúsculos simples (prima naturalia) que as compõem (p. 326). Depois dessa agregação inicial, posteriores agregações formam corpos cada vez maiores. Quando os agregados aderem uns aos outros, o tamanho e, frequentemente, a figura dos agregados, compostos pela sua justaposição e coesão, é alterada e não raramente o movimento também (cf. Boyle, 2000, v. 5, p. 326).

A partir do momento em que existe a agregação primária surge um novo atributo mecânico da matéria, que é a textura. Essa propriedade pode ser definida como certa disposição das partes no todo (cf. Boyle, 2000, v. 5, p. 316). Ela não está presente nos corpúsculos últimos da matéria, apenas a partir de suas agregações. Essa afecção mecânica está presente tanto nos agregados (concreções primárias), devido à disposição dos corpúsculos simples (minima naturalia), como nos corpos do mundo macroscópi- 
cos devido à disposição dos agregados que os constituem. É essa mesma disposição dos corpúsculos dentro do agregado e, consequentemente, dos agregados dentro de concreções superiores até o mundo macroscópico, que torna possível a interação de uma porção de matéria com outra, em uma relação no estilo chave/fechadura (p. 310). No mundo macroscópico, o efeito dessa interação aparece na forma de qualidades não mecânicas, como, por exemplo, as qualidades químicas (solubilidade, acidez, corrosão etc.), médicas (efeito de unguentos, remédios, venenos etc.) ou sensíveis (cor, odor, paladar etc.). O fato de que Boyle não recorre aos corpúsculos para explicar as qualidades do mundo, mas sim à textura das agregações de corpúsculos (cf. Anstey, 2000) é o que torna o mecanicismo boyleano algo suis generis e sofisticado, quando comparado com outras teorias mecanicistas de sua época.

As experiências químicas de Boyle são uma maneira de realizar alterações na textura dos corpos e, consequentemente, nas suas qualidades. Nessa condição, então, não existe nada que seja efetivamente gerado ou corrompido. Quando um corpo é aparentemente destruído e outro gerado em um processo químico, por exemplo, o que acontece é que o mesmo corpo existe de outro modo, ou seja, existe com uma diferente disposição de suas partes. Nada é substancialmente produzido, apenas ocorre uma alteração espacial da matéria que já existia (cf. Boyle, 2000, v. 5, p. 328).

\section{A ÁGUA RÉGIA}

A descoberta da água régia é tradicionalmente atribuída ao alquimista Geber. Ele comenta que a adição de sal amoníaco (Cloreto de Amônio, $\mathrm{NH}_{4} \mathrm{OH}$ ) em água forte (ácido nítrico, $\mathrm{HNO}_{3}$ ) pode dissolver o ouro, um metal incrivelmente resistente à corrosão (cf. Goldfarb, 1987, p. 143). Atualmente, a água régia é comumente obtida pela mistura de ácido nítrico $\left(\mathrm{HNO}_{3}\right)$ e de ácido clorídrico $(\mathrm{HCl})$, geralmente em uma proporção de 1:4. A reação de corrosão do ouro pela água régia - e subsequente precipitação por carbonato de potássio $\left(\mathrm{K}_{2} \mathrm{CO}_{3}\right)$ - é descrita por Lawrence Principe na citação a seguir.

Usando a equação padrão, porém super-simplificada, água régia = uma mistura de ácido clorídrico e nítrico, e tártaro calcinado = carbonato de potássio, nós descobrimos que nossa cal é meramente óxido de ouro, por meio das seguintes equações:

$$
\begin{gathered}
\mathrm{Au}+\mathrm{HNO}_{3}+4 \mathrm{HCl} \rightarrow \mathrm{AuCl}_{3} \cdot \mathrm{HCl}+\mathrm{NO}+2 \mathrm{H}_{2} \mathrm{O} \\
2 \mathrm{AuCl}_{3} \cdot \mathrm{HCl}+4 \mathrm{~K}_{2} \mathrm{CO}_{3} \rightarrow 8 \mathrm{KCl}+\mathrm{H}_{2} \mathrm{O}+4 \mathrm{CO}_{2}+\mathrm{Au}_{2} \mathrm{O}_{3}
\end{gathered}
$$

Contudo, já que a constituição química (...) (Principe, 1987, p. 22, grifo nosso). ${ }^{2}$

2 A reação apresentada na citação diz respeito a um sistema com baixa concentração de ácido nítrico, pois óxido nítrico (NO) está sendo formado. Em altas concentrações de $\mathrm{NO}_{3}^{-}$, ocorrerá a formação de dióxido de nitrogênio $\left(\mathrm{NO}_{2}\right)$. 
A tradução química de experimentos alquímicos envolvendo água régia em Robert Boyle

Está claro aqui que a corrosão do ouro é devida à formação de $\mathrm{AuCl}_{3} \cdot \mathrm{HCl}$, que é dissolvido na sua forma iônica $\left[\mathrm{AuCl}_{4}\right]^{-}$e $\mathrm{H}^{+}$. A forte oxidação por ácido nítrico deve ser associada a algum tipo de fonte de agente complexante como os íons cloreto, $\mathrm{Cl}^{-}$, que formam com o ouro o complexo $\left[\mathrm{AuCl}_{4}\right]^{-}$. A atuação conjunta de ambos, o ácido nítrico e o agente complexante, é necessária, pois cada um deles possui uma função específica nesse processo.

O ácido nítrico é um poderoso oxidante que vai dissolver pequenas quantidades de ouro, formando íons de ouro $\left(\mathrm{Au}^{3+}\right)$. O ácido clorídrico é um excelente exemplo de fonte de íons cloreto $\left(\mathrm{Cl}^{-}\right)$, os quais funcionam como agentes complexantes, mas que pode ser substituída por outras fontes, como veremos adiante. Esses íons cloreto vão reagir com o ouro para produzir ânions cloroauratos $\left(\left[\mathrm{AuCl}_{4}\right]^{-}\right)$.

A contínua remoção de íons de ouro da solução e a liberação em sistema aberto de $\mathrm{NO}_{2}$ deslocam a reação para a direita até que todo o ouro seja dissolvido. A reação, considerando um sistema com ácido nítrico concentrado, pode ser descrita da seguinte maneira:

$$
\begin{gathered}
\mathrm{Au}_{(\mathrm{s})}+3 \mathrm{NO}_{3}^{-{ }_{(\mathrm{aq})}}+6 \mathrm{H}^{+}{ }_{(\mathrm{aq})} \rightarrow \mathrm{Au}^{3+}{ }_{(\mathrm{aq})}+3 \mathrm{NO}_{2(\mathrm{~g})}+3 \mathrm{H}_{2} \mathrm{O}_{(\mathrm{l})} \\
\mathrm{Au}^{3+}{ }_{(\mathrm{aq})}+4 \mathrm{Cl}^{-}{ }_{(\mathrm{aq})} \rightarrow\left[\mathrm{AuCl}_{4}\right]^{-}{ }_{(\mathrm{aq})}
\end{gathered}
$$

Boyle diversas vezes mistura outros materiais que são fonte de íons cloreto com o ácido nítrico, formando água régia.

\section{Alguns exemplos de PRodução de ÁGUA RÉGia nos Diários de trabalho}

Muitos exemplos de obtenção de água régia podem ser encontrados nos Diários de trabalho (Workdiaries) e uma série deles foi reproduzida nos trabalhos publicados. No diário de número 19, Boyle descreve um processo no qual o ácido clorídrico (no texto descrito como espírito do sal), sendo destilado de salitre bruto, estava tão alterado e vigorado que poderia dissolver inclusive ouro, "como a água régia":

Eu descobri (...) que o bom espírito do sal, sendo destilado de salitre bruto, foi, devido a isso, tão alterado e fortificado que, apesar de não muito facilmente, dissolveu ouro bruto (...) e como a água régia, ele precipita cristais de prata (WD, 19, item 8). 
Boyle acreditava que uma alteração na textura do espírito do sal estava fazendo com que o mesmo adquirisse um poder que antes ele não tinha, "tornando-o como" água régia. A destilação do salitre em um meio ácido gera o espírito do nitro. Em notação de química contemporânea a reação pode ser descrita como:

$$
\mathrm{H}_{(\text {aq) }}^{+}+\mathrm{KNO}_{3(\mathrm{~s})} \rightarrow \mathrm{HNO}_{3(\text { volátil) }}+\mathrm{K}_{(\text {aq) }}^{+}
$$

A mistura de ácido nítrico e ácido clorídrico é propriamente água régia,

$$
\mathrm{HCl}_{(\mathrm{aq})}+\mathrm{HNO}_{3(\mathrm{aq})}=\text { água régia }
$$

Experimentos similares podem ser encontrados no mesmo diário 19, itens 9 e 10. Essa nova mistura podia agora dissolver ouro e, como esperado, não a prata, pois a mesma será oxidada pelo ácido nítrico, e os seus íons irão reagir com os íons cloreto $\left(\mathrm{Cl}^{-}\right)$, formando cloreto de prata que irá precipitar. Boyle se refere a eles como cristais de prata (crystals of silver) que são insolúveis em água forte. A notação contemporânea é:

$$
\mathrm{H}^{+}{ }_{(\mathrm{aq})}+\mathrm{Cl}^{-}{ }_{(\mathrm{aq})}+\mathrm{NO}_{3}{ }_{(\mathrm{aq})}^{-}+\mathrm{Ag}^{+}{ }_{(\mathrm{aq})} \rightarrow \mathrm{AgCl}_{(\mathrm{s})}+\mathrm{H}^{+}{ }_{(\mathrm{aq})}+\mathrm{NO}_{3}{ }_{(\mathrm{aq})}^{-}
$$

Boyle acreditava que esse experimento provava que o espírito do sal poderia ser modificado pela destilação com salitre, de tal maneira que se tornasse como água régia. Ele acreditava que essa mudança ocorria devido às alterações na textura do espírito do sal pela destilação com salitre. Essa modificação ocorria de tal forma que o resultante atuasse "como a água régia", inclusive produzindo cristais de prata.

Boyle apresenta no diário 15 , item 13 , outra reação, porém desta vez com tricloreto de antimônio $\left(\mathrm{SbCl}_{3}\right)$, que é mencionado no texto e conhecido na época como manteiga de antimônio.

Tome-se uma boa manteiga de antimônio pura e nela adicione-se pouco a pouco bom espírito do nitro (...) redestile 2 ou 3 vezes o material em um destilador (...) nesse mênstruo dissolva-se ouro foliado puro (WD, 15 , item 13 ).

O tricloreto de antimônio $\left(\mathrm{SbCl}_{3}\right)$ pode ser dissolvido em uma solução de ácido nítrico $\left(\mathrm{HNO}_{3}\right)$. Essa solução contém, além de antimônio, íons cloreto, nitrato e hidrogênio. Essa é a mesma composição química da água régia.

$$
\text { (solução) } \mathrm{SbCl}_{3(\mathrm{~s})}+\mathrm{HNO}_{3(\mathrm{aq})} \rightarrow \mathrm{Sb}^{3-}{ }_{(\mathrm{aq})}+\mathrm{H}_{(\mathrm{aq})}^{+}+\mathrm{NO}_{3}^{-{ }_{(\mathrm{aq})}}+3 \mathrm{Cl}_{(\mathrm{aq})}^{-}
$$


A tradução química de experimentos alquímicos envolvendo água régia em Robert Boyle

$$
\text { (água régia) } \mathrm{HNO}_{3(\mathrm{aq})}+3 \mathrm{HCl}_{(\mathrm{aq})} \rightarrow 4 \mathrm{H}_{(\mathrm{aq})}^{+}+\mathrm{NO}_{3{ }_{(\mathrm{aq})}^{-}}+3 \mathrm{Cl}^{-}{ }_{(\mathrm{aq})}
$$

O tricloreto de antimônio é fonte de íons cloreto e, por isso, essa mistura pode dissolver ouro, o que a torna quimicamente similar à água régia. No diário 15, item 24, Boyle, usando seus termos, afirma que a mera mistura de espírito do sal e espírito do nitro pode ser usada no lugar de água régia e que isso funciona da mesma maneira. "Tome-se três partes de bom espírito de sal comum para uma parte de bom espírito do nitro e utilize-se essa mistura no lugar de água régia" (WD, 15, item 24). Segundo a notação contemporânea, temos:

$$
\mathrm{HNO}_{3(\mathrm{aq})}+3 \mathrm{HCl}_{(\mathrm{aq})} \rightarrow 4 \mathrm{H}_{(\mathrm{aq})}^{+}+\mathrm{NO}_{3}{ }_{(\mathrm{aq})}^{-}+3 \mathrm{Cl}^{-}{ }_{(\mathrm{aq})}
$$

Esse é um procedimento que faz a mistura possuir as mesmas propriedades da água régia. Funciona pela mesma razão já mencionada, ou seja, que o ácido nítrico é um forte oxidante e o ácido clorídrico é fonte de íons cloreto para formar $\left[\mathrm{AuCl}_{4}\right]^{-}$, quando o ouro é adicionado.

\section{A produção de ÁGUA régia na obra Para o bem da humanidade}

Boyle, na obra Para o bem da humanidade (That the goods of mankind), inicialmente publicada em 1671, cita uma reação de formação de água régia. Algumas vezes a solução de cobre em ácido nítrico pode ser usada para colorir ossos ou marfim. A adição posterior de sal amoníaco $\left(\mathrm{NH}_{4} \mathrm{Cl}\right)$ transforma o material (água forte) em água régia: "torna-a [a água forte] em água régia, e nisso faz uma solução de ouro, com a qual é possível tingir facas, adagas ou caixas de marfim (...) com uma bela cor púrpura" (Boyle, 2000, v. 6 , p. 474).

A razão é evidente, o sal amoníaco $\mathrm{NH}_{4} \mathrm{Cl}^{-}$adicionado ao ácido nítrico $\mathrm{HNO}_{3}{ }^{-}$ tornar-se-á fonte de íons cloreto na solução. Essa mistura química de ácido clorídrico e ácido nítrico possui poderes já discutidos anteriormente.

$$
\begin{gathered}
\mathrm{NH}_{4} \mathrm{Cl}_{(\mathrm{s})}+\mathrm{HNO}_{3(\mathrm{~s})} \rightarrow \mathrm{NH}_{4}^{+}{ }_{(\mathrm{aq})}+\mathbf{H}^{+}{ }_{(\mathrm{aq})}+\mathbf{C l}^{-}{ }_{(\mathrm{aq})}+\mathbf{N O}_{3}^{-}{ }_{(\mathrm{aq})} \text { (mistura descrita) } \\
\mathrm{HCl}_{(\mathrm{aq})}+\mathrm{HNO}_{3(\mathrm{aq})} \rightarrow{ }_{2} \mathbf{H}_{(\mathrm{aq})}^{+}+\mathbf{C l}^{-}{ }_{(\mathrm{aq})}+\mathbf{N O}_{3}^{-}{ }_{(\mathrm{aq})} \text { (água régia) }
\end{gathered}
$$

O interessante aqui é que Boyle admite que esse procedimento transforma o material em água régia. Ele está expressamente admitindo a transformação, não apenas apontando algo com características similares, ou seja, na sua compreensão, o que ocorre é uma mudança de qualidades pela modificação da textura. 


\section{A obtençÃo de Alguns SAIs transmutados E A ÁGUA RÉGIA}

A obtenção do nitrato de sódio (salitre do Chile) é comentada na obra Origem das formas e das qualidades, na qual a formação da água régia é notada como uma indicação na alteração da textura do corpo. Aqui a produção de água régia não é o objetivo final, mas apenas um fator acidental que é usado para provar que uma transmutação realmente ocorreu no processo. Segue-se o trecho:

para apresentar o quão próximas de uma real transmutação essas mudanças podem mostrar-se (...) pelo recesso de algumas partículas (...) e da nova textura do resíduo (...). Tome-se uma parte de bom sal marinho bem seco e em pó e adicione-se o dobro de seu peso de boa água forte, ou espírito do nitro, tendo-os em digestão por algum tempo, destile-os em fogo baixo em um destilador (...) até que a matéria remanescente esteja bem seca (...) essa substância que reside no fundo do vidro é o que queremos (...). Pois, em primeiro lugar, podemos notar que o líquido destilado não é mais uma água forte, ou espírito do nitro, mas uma água régia que é capaz de dissolver ouro enquanto a água forte não o irá dissolver (...). Então, o gosto da substância proveniente dessa operação foi muito alterado. Pois ela não possui aquela forte salinidade que tinha antes, mas um gosto muito mais moderado (...) afeta o paladar muito mais como o salitre do que como o sal comum (...). Em seguida, apesar de que este último corpo é de difícil fusão, nosso sal artificial imita o salitre sendo de fácil fusão (Boyle, 2000, v. 5, p. 410).

O sal marinho é usado aqui como fonte de íons cloreto. A adição de sal marinho (cloreto de sódio, $\mathrm{NaCl}$ ) no sistema fornece íons cloreto para o ácido nítrico. Quando o material é destilado, a mistura de água régia é obviamente obtida já que o ácido nítrico e o ácido clorídrico são evaporados por aquecimento e depois resfriados e coletados. Quando o material é seco na retorta, um novo sal está presente e seria provavelmente o nitrato de sódio.

$$
2 \mathrm{H}^{+}{ }_{(\text {aq })}+2 \mathrm{Na}^{+}{ }_{(\text {aq })}+\mathrm{Cl}^{-}{ }_{(\text {aq })}+3 \mathrm{NO}_{3}^{-{ }_{(\text {aq })}} \rightarrow \mathrm{HCl}_{(\text {volátil) }}+\mathrm{HNO}_{3 \text { (volátil) }}+2 \mathrm{NaNO}_{3 \text { (s) }}
$$

Boyle decide analisar o sal que restou na retorta e nota que não é o mesmo sal que foi adicionado, ou seja, que não é mais sal marinho. Percebe-se isso por duas principais razões: o sal não impressiona tanto o paladar (muito menos salgado) e existe uma enorme diferença no ponto de fusão do novo sal.

Todos os pontos indicados por Boyle levam um químico atual a supor que o novo material é realmente nitrato de sódio, o qual é um sal branco que afeta menos o palato 
e funde a $3 \circ \eta^{\circ} \mathrm{C}$. A diferença com o cloreto de sódio é grande, ou seja, ele também é um sal branco, mas muito mais salgado e com um ponto de fusão de $801^{\circ} \mathrm{C}$. Essa diferença na fusibilidade e na afecção do palato indica claramente um novo sal. A associação com o salitre era inevitável, já que são materiais muito parecidos, como mostra a Tabela 1.

\section{Sal}

Cloreto de Sódio

Nitrato de Potássio

Nitrato de Sódio

\section{Fórmula Molecular}

$\mathrm{NaCl}$

$\mathrm{KNO}_{3}$

$\mathrm{NaNO}_{3}$

\section{Afetação do Palato}

Muito

Moderado

Moderado

\section{Ponto de Fusão $\left({ }^{\circ} \mathrm{C}\right)$}

801

334

$3 \circ 7$

Tabela ı: Diferenças entre salitre $\left(\mathrm{KNO}_{3}\right)$ e salitre do Chile $\left(\mathrm{NaNO}_{3}\right)$

Podemos, então, afirmar que a diminuição do ponto de fusão é provavelmente devida à formação de nitrato de sódio. Note-se como Boyle, por prudência, evita uma afirmação categórica de que o novo sal é salitre, limitando-se a dizer que ele imita o salitre. É possível que o sal contivesse alguma impureza, afinal Boyle não trabalhava com reagentes puros como se trabalha hoje, porém, mesmo que esse sal contenha alguma impureza, é muito difícil não supor que o material principal é realmente salitre do Chile $\left(\mathrm{NaNO}_{3}\right)$ e que, de fato, Boyle faz referência ao salitre propriamente dito, o qual é um material amplamente conhecido.

Tentando ainda provar que esse novo material comportava-se muito mais como o salitre, Boyle o submete ao mesmo procedimento do salitre no Ensaio do nitro (Essay of nitre), publicado pela primeira vez em 1661. Ele queimou o sal com carvão, mostrando que esse novo material poderia adquirir um comportamento alcalino, classe de elementos que ele chamava de álcali.

E, para futuros testes, tendo derretido uma boa quantidade desse sal marinho transmutado em um cadinho, adicionando a ele pequenos fragmentos de carvão em brasa, iria como o nitro (...) gerar uma chama (...). Porém, isso não é a maior descoberta pela qual eu planejei esse experimento. Pois eu pretendo aqui desenvolver um processo para transformar um sal ácido em um álcali (Boyle, 2000, v. 5 , p. 411).

Boyle, em outro trabalho, usa o carvão para transformar esse mesmo sal. É exatamente o que ele faz na obra Produtibilidade dos princípios químicos (Producibleness of chymical principles), inicialmente publicada em 1680, com o propósito de mostrar como é fácil destruir um sal. $\mathrm{O}$ experimento está proposto como segue. 
Nós adicionamos um sal marinho em pó e bem seco em um destilador, algumas vezes [com peso] igual, outras vezes (o que eu prefiro) com o dobro do peso de bom espírito do nitro, ou água forte, e destilamos tudo lentamente. Retiramos o sal seco remanescente no fundo, o qual encontramos muito modificado, tanto na cor (...) como no gosto, que era muito diferente do que se tinha antes (...). Sendo esse sal pulverizado (...) e posto em um cadinho, colocado em um fogo conveniente, pela repetida adição de fragmentos e de carvão em brasa (...), o material remanescente sendo retirado parecia ter em grande parte uma natureza alcalina, pois tinha um gosto adstringente na língua. Caso o espírito do nitro ou água forte fosse adicionado a ele, uma grande ebulição iria ocorrer, ele tornaria verde o xarope de violetas e, resumindo, exibiria diversos fenômenos de sal alcalino (Boyle, 2000 , v. 9, p. 44).

O primeiro passo da reação foi misturar o sal marinho com o ácido nítrico, formando nitrato de sódio como se viu anteriormente. Uma maneira contemporânea de descrever o fato ocorrido quimicamente seria:

$$
\mathrm{NaCl}_{(\mathrm{s})}+\mathrm{HNO}_{3(\mathrm{aq})} \rightarrow \mathrm{NaNO}_{3(\mathrm{~s})}+\mathrm{HCl}_{(\text {volátil })}
$$

O sal restante é diferente, ou seja, o nosso já citado nitrato de sódio ou salitre do Chile. A diferença é notada por alterações em propriedades como gosto, fusibilidade e até mesmo a cor é citada. O segundo passo é reagir o sal com o carvão e com o ar (Boyle não acreditava que o carvão reagia, achava que era apenas uma fonte de calor):

$$
{ }_{2} \mathrm{NaNO}_{3(\mathrm{~s})}+\mathrm{C}_{(\mathrm{s})}+\mathrm{O}_{2(\mathrm{~g})}+\mathrm{H}_{2} \mathrm{O}_{(\mathrm{l})} \rightarrow \mathbf{N a}_{2} \mathbf{C O}_{3(\mathrm{~s})}+2 \mathrm{HNO}_{3 \text { (volátil) }}
$$

O sal resultante é o carbonato de sódio, um sal alcalino. Esse sal vai reagir com um ácido forte, gerando bolhas, efervescência e barulho devido à liberação de gás carbônico (como Boyle indica). A reação está descrita abaixo em termos atuais.

$$
2 \mathrm{H}_{(\mathrm{aq})}^{+}+\mathrm{Na}_{2} \mathrm{CO}_{3(\mathrm{~s})} \rightarrow 2 \mathrm{Na}_{(\mathrm{aq})}^{+}+\mathrm{H}_{2} \mathrm{O}_{(\mathrm{l})}+\mathrm{CO}_{2(\mathrm{~g})}
$$

Esse novo sal alcalino tornará verde o xarope de violetas (típico teste para identificar materiais alcalinos) e terá o mesmo gosto de qualquer outro carbonato na língua, ou seja, adstringente. Boyle se utiliza frequentemente de testes organolépticos, aparência visível e testes químicos para identificar seu material.

Um ponto a ser considerado é que, na obra que trata da produção dos princípios químicos, Boyle cria uma técnica, cujo objetivo principal é o desenvolvimento de um 
A tradução química de eXPerimentos Alquímicos envolvendo ÁGUa régia em Robert Boyle

método para transformar um sal ácido em um álcali (cf. Boyle, 2000, v. 9, p. 39-47). Isso revela seu procedimento metodológico de trabalho. Ele utiliza as informações adquiridas nos experimentos para desenvolver tecnologias de transformação química. É importante notar como Boyle usa esses exemplos para defender que a alteração na textura dos corpos é a responsável pela alteração em suas qualidades.

\section{A NATUREZA dos ESPÍritos E O EFEITO DA ÁGUA RÉGIA}

Outro exemplo relacionado com a água régia pode ser encontrado na obra História da fluidez e da solidez (The history of fluidity and firmness), publicada primeiramente em 1659. Nesse tratado, Boyle tenta associar experimentos químicos às noções de filosofia da natureza, para dar conta da fluidez e solidez dos corpos. Ele considera alguns pontos.

Um corpo parece ser fluido, basicamente, por causa disto: ele consiste em corpúsculos 3 que tocam uns nos outros apenas em algumas partes de suas superfícies (sendo então descontínuo todo o resto) e, separadamente agitados, podem, em razão de seus numerosos poros ou espaços necessariamente deixados entre suas partes descontínuas, facilmente deslizar pelas superfícies uns dos outros. Por motivo de seus próprios movimentos difusos irão mover-se até que encontrem com algum corpo duro e resistente (...) que os acomode (Boyle, 2000, v. 2, p. 120).

Boyle explica a fluidez e a firmeza pela posição, movimento e estrutura dos agregados. Para defender sua teoria, ele utiliza um experimento alquímico. Coloca a dissolução de mercúrio, chumbo ou ouro em água régia como um exemplo, já que no início eles vão para o fundo e, então, começam a subir com a agitação da corrosão e não afundam mais. As pequenas partes são carregadas livremente. A agitação e o movimento separam as partes do metal em partes menores. Boyle afirma que a primeira condição para a fluidez é a pequenez dos componentes do corpo.

A primeira [condição para a fluidez] é a pequenez dos corpos que compõem um corpo (...) o volume por ele mesmo é apto a fazê-los tão pesados que eles não possam ser agitados por (...) aquelas causas que fazem as menores partes dos corpos fluídos moverem-se tão livremente para cima e para baixo (...) a pequenez

3 Em alguns casos específicos, Boyle chama os constituintes compostos estáveis de um corpo de corpúsculo, mas isso corresponde ao que é chamado neste artigo de agregado. 
das partes pode facilitar eles serem facilmente colocados em movimento e mantidos assim (Boyle, 2000, v. 2, p. 122).

O outro exemplo é sobre o estômago que pode dissolver sólidos em líquidos, separando as partes, deixando-as ainda menores. Em teoria, isso é o mesmo que ocorre na destilação, pois "o fogo não faz mais do que separar as partes aquosas ou líquidas do restante, as quais estavam misturadas no material inicial, trazendo-as juntas no recipiente coletor" (Boyle, 2000, v. 2, p. 124).

Boyle também aceita que um sólido pode ser quebrado em pequenos pedaços quando em movimento, tornando-se um líquido, como quando sal marinho e vitríolo de cal (basicamente sulfato de cálcio) ficam líquidos por ação do fogo, mesmo quando não mais tiverem partes líquidas. Espíritos e substâncias voláteis, provavelmente, possuem partes pequenas. Um exemplo digno de menção é quando o vinho congela. Nas palavras de Boyle, "o líquido que permanece não congelado é mais sutil e espirituoso" (cf. Boyle, 2000 , v. 2, p. 125), ou seja, é mais difícil de ser congelado por possuir partes menores. A explicação da química contemporânea para esse fenômeno é que o vinho é um tipo de mistura de água e álcool etílico e quando é resfriado, a água congela primeiro (já que o ponto de fusão da água é $\circ^{\circ} \mathrm{C}$ ), enquanto o álcool etílico, que é um material mais volátil, permanece líquido (ponto de fusão do álcool etílico é - $114,3^{\circ} \mathrm{C}$ ). Isso faz sentido já que, geralmente, substâncias voláteis possuem pontos de fusão mais baixos.

Boyle deduz que os espíritos salinos consistem em pequenos grãos de sal. Para provar isso, ele mostra que o sal amoníaco pode ser obtido do espírito da urina (amônia ou carbonato de amônio) e espírito do sal. Nos termos contemporâneos, isso quer dizer que o cloreto de amônio pode ser obtido via uma solução de hidróxido de amônio $\left(\mathrm{NH}_{4} \mathrm{OH}\right)$, carbonato de amônio $\left[\left(\mathrm{NH}_{4}\right)_{2} \mathrm{CO}_{3}\right]$ e ácido clorídrico:

$$
\mathrm{NH}_{4} \mathrm{OH}_{(\mathrm{aq})}+\left(\mathrm{NH}_{4}\right)_{2} \mathrm{CO}_{3(\mathrm{aq})}+3 \mathrm{HCl}_{(\mathrm{aq})} \rightarrow 3 \mathrm{NH}_{4} \mathrm{Cl}_{(\mathrm{s})}+\mathrm{CO}_{2(\mathrm{~g})}+2 \mathrm{H}_{2} \mathrm{O}_{(\mathrm{l})}
$$

Para Boyle, (em seus termos) esses espíritos juntos podem rearranjar a textura de seus agregados de forma a fazer um material sólido, ou seja, um sal e não mais um fluido (cf. Boyle, 2000 , v. 2, p. 125). Isso ocorre, provavelmente, porque as pequenas partes estão convergindo de modo a formar partes grandes, perdendo assim movimento. Ele diz que o procedimento é simples, ou seja, é como obtê-lo de sal bruto e é tão fácil colocar os espíritos juntos como separá-los.

O que é mais interessante é o quanto Boyle tenta mostrar como a dissolução de ouro por água régia pode ser usada para defender sua teoria. $\mathrm{O}$ ácido nítrico (citado por ele no texto como água forte) pode dissolver ouro também, mas apenas se for adiciona- 
A tradução química de experimentos Alquímicos envolvendo Água régia em Robert Boyle

do ácido clorídrico (citado por ele no texto como espírito do sal), porque, obviamente, água régia está sendo formada. Como diz Boyle,

eu observei que (...) a água forte comum pode ser capacitada a dissolver ouro (...) pela adição de espírito do sal; então eu descobri que sal bruto comum, ainda mal dissolvido em água forte, irá dar a ela o poder de agir sobre o ouro. E, por outro lado, (...) nitro bruto dissolvido em bom espírito de sal pode servir como água régia (Boyle, 2000, v. 2, p. 125).

Boyle mostra (em seus termos) como o sal e o espírito do sal têm similaridades químicas, supondo que a diferença entre a firmeza e a fluidez deles é apenas uma questão do tamanho das partículas (que permitem diferentes graus de movimentos). Se espírito do nitro for adicionado ao espírito do sal, tal mistura permite dissolver o ouro. A mesma coisa ocorre adicionando sal marinho ao espírito do nitro (também conhecido como espírito do salitre) ou adicionando salitre ao espírito do sal. De qualquer maneira, quimicamente, água régia é formada. Em termos da química contemporânea, o que ocorre é que não importa se cloreto de sódio $(\mathrm{NaCl})$ é adicionado a ácido nítrico $\left(\mathrm{HNO}_{3}\right)$ ou nitrato de potássio $\left(\mathrm{KNO}_{3}\right)$ é adicionado a ácido clorídrico ( $\left.\mathrm{HCl}\right)$, de qualquer maneira vai ocorrer a formação de água régia.

$$
\begin{gathered}
\text { (espírito do sal + espírito do nitro) } \mathrm{HCl}_{(\mathrm{aq})}+\mathrm{HNO}_{3(\mathrm{aq})} \rightarrow{ }_{2} \mathbf{H}_{(\mathrm{aq})}^{+}+\mathrm{Cl}_{(\mathrm{aq})}^{-}+\mathrm{NO}_{3}^{-}(\mathrm{aq}) \\
\left(\text { sal marinho + espírito do nitro) } \mathrm{NaCl}_{(\mathrm{s})}+\mathrm{HNO}_{3(\mathrm{aq})} \rightarrow \mathrm{Na}_{(\mathrm{aq})}^{+}+\mathbf{H}_{(\mathrm{aq})}^{+}+\mathrm{Cl}_{(\mathrm{aq})}^{-}+\mathrm{NO}_{3}^{-}(\mathrm{aq})\right. \\
\left(\text { salitre + espírito do sal) } \mathrm{KNO}_{3(\mathrm{~s})}+\mathrm{HCl}_{(\mathrm{aq})} \rightarrow \mathrm{K}_{(\mathrm{aq})}^{+}+\mathbf{H}_{(\mathrm{aq})}^{+}+\mathrm{Cl}_{(\mathrm{aq})}^{-}+\mathbf{N O}_{3}^{-}{ }_{(\mathrm{aq})}\right.
\end{gathered}
$$

Para Boyle, os respectivos sais estão fazendo, quimicamente, os papéis dos espíritos que eles originaram. Isso é uma evidência de que os espíritos são apenas sais fluidos, pois são formados por partes muito menores e mais agitadas. Para Boyle, não existe diferença química entre sais e seus respectivos espíritos, exceto pelo tamanho de suas partes. $\mathrm{O}$ fato de que esses ácidos podem ser formados a partir desses sais não poderia ser uma mera coincidência. O próprio processo de destilação estaria apenas separando pequenas partes do sal, que agora são mais violentamente agitadas, tornando-as voláteis. Para a química contemporânea, não é isso que ocorre, mas sim a formação de materiais voláteis de acordo com a notação abaixo:

$$
\begin{gathered}
\mathrm{NaCl}_{(\mathrm{s})}+\mathrm{H}_{(\text {aq) }}^{+} \rightarrow \mathrm{Na}_{(\text {aq) }}^{+}+\mathrm{HCl}_{(\text {volátil) }} \text { (formando espírito do sal) } \\
\mathrm{KNO}_{3(\mathrm{~s})}+\mathrm{H}_{(\mathrm{aq})}^{+} \rightarrow \mathrm{K}_{(\mathrm{aq})}^{+}+\mathrm{HNO}_{3 \text { (volátil) }} \text { (formando espírito do nitro) }
\end{gathered}
$$


As notações de Boyle na qual a capacidade de dissolver ouro é testada com diferentes substâncias (como a mistura de ácidos com outros ácidos ou sais com ácidos para obter substâncias como a água régia) podem ser encontradas também nos Diários de trabalho cujas reações já foram vistas previamente neste trabalho.

Outro exemplo de alteração de textura é dado no História da fluidez e da solidez (cf. Boyle, 2000 , v. 2, p. 478, experimento x). Boyle afirma que o espírito do sal e a prata são dissolvidos juntos em água forte, porém o produto de ambos não é. Caso seja misturada prata na solução com espírito do sal, é possível encontrar um precipitado branco. De acordo com a química contemporânea o que ocorre é que o ácido clorídrico e a prata são dissolvidos juntos em ácido nítrico, formando cloreto de prata que é insolúvel no solvente.

$$
\mathrm{Ag}_{(\mathrm{aq})}^{+}+\mathrm{HCl}_{(\mathrm{aq})} \rightarrow \mathrm{AgCl}_{(\mathrm{s})}+\mathrm{H}_{(\mathrm{aq})}^{+}
$$

Esse material é seco e derretido em fogo moderado, obtendo-se assim o material chamado na época de Boyle de luna cornea e que, quimicamente, não passa de uma massa seca de cloreto de prata sólida, conhecida pela sua baixa solubilidade em água e em alguns outros ácidos. Boyle atenta que

apesar de que ambos, os espíritos de sal e a prata dissolvida em água forte, podem facilmente ser dissolvidos em simples água, nossa luna cornea não apenas não dissolve em água, como também é tão indisposta para solução, que me lembro que eu havia mantido a mesma em digestão, um pouco em água forte e um pouco em água régia, por um bom tempo e com um razoável grau de calor, sem conseguir dissolvê-la como um metal (Boyle, 2000, v. 2, p. 478).

Então, Boyle chama a atenção para o fato de que o produto obtido é muito mais insolúvel do que os reagentes que são totalmente solúveis em água forte. Isso é uma evidência de um rearranjo de suas partes que gerou uma nova característica de fixidez, tornando o produto insolúvel. O processo alquímico levou a uma micro-reorganização mecânica da textura, alterando as propriedades do material.

A mesma reação é usada no Origens mecânicas das qualidades (Mechanical origin of qualities) (cf. Boyle, 2000, v. 8), obra inicialmente publicada entre $1675^{-} 76$, porém com um objetivo diferente, ou seja, o de mostrar como a corrosão pode ser mecanicamente produzida pela adição de um novo agregado. Na seção seguinte, mostra-se como Boyle, no mesmo livro, apresenta a adição de sal marinho em ácido nítrico (formando água régia e permitindo a dissolução de ouro), corroborando a ideia de que a origem da corrosão é mecânica. 
A tradução química de eXPerimentos Alquímicos envolvendo ÁGUa régia em Robert Boyle

\section{A obtenção De ÁGUA RÉGia no Origens mecânicas das qualidades}

Por meio de experimentos químicos, Boyle defende que a corrosão pode ser mecanicamente produzida. Ele nota que os ácidos, quando aquecidos, podem corroer os metais muito mais rapidamente, indicando uma explicação mecânica para a corrosão, já que a adição de mais velocidade às partículas do ácido implica um aumento na velocidade do processo. Isso está expresso no trecho a seguir:

É observado por refinadores, ourives e químicos que a água forte e a água régia, que são mênstruos corrosivos, dissolvem metais. A primeiro dissolve prata e a última ouro, muito mais rapida e abundantemente quando um calor externo dá ao movimento interno um novo grau de veemência ou velocidade (Boyle, 2000, v. 8, p. 461 ).

Esse exemplo é claramente usado para expressar a filosofia mecânica de Boyle, corroborando fortemente a hipótese corpuscular. Além disso, existe o fato de que a água régia pode ser formada por um procedimento químico, simplesmente dissolvendo, em ácido nítrico, o sal marinho ( $\mathrm{NaCl}$ ), o ácido clorídrico (HCl) ou mesmo o cloreto de amônio $\left(\mathrm{NH}_{4} \mathrm{Cl}\right)$. Nos termos de Boyle, isso corresponde à dissolução, em espírito do nitro, de sal marinho, espírito do sal ou sal amoníaco. Ele usa esse exemplo químico para sustentar sua teoria da mesma forma que usa a evidência do aquecimento físico, aparentemente, igualando o status filosófico das explicações químicas e físicas. No trecho abaixo, Boyle apresenta a conclusão dos experimentos até então realizados.

Pelos testes anteriores pareceu que o aumento do movimento nos corpúsculos mais penetrantes de um líquido contribui muito para seu poder dissolutivo; e eu acrescentarei agora que a forma e o tamanho, que são afecções mecânicas e, algumas vezes, também a solidez desses mesmos corpúsculos qualificam um líquido a dissolver este ou aquele corpo particular. Disso, mesmo algumas das práticas mais familiares dos químicos podem fornecer-nos exemplos. Pois não existe explicação mais provável que pode ser dada para a suposição de por que a água forte, que dissolverá a prata, sem interagir com o ouro, deveria, por adição de uma quarta parte do seu peso de sal amoníaco, ser transformada em água régia, que, sem interagir com a prata, dissolverá o ouro. Mas não há necessidade de recorrer a um corpo tão bruto e composto como sal amoníaco para capacitar água forte a dissolver ouro, pois, o espírito de sal comum sozinho, sendo misturado na devida proporção, será suficiente para esse propósito (Boyle, 2000, v. 8, p. 464). 


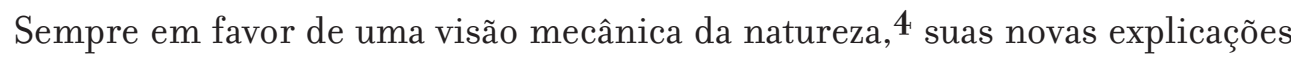
usam exemplos alquímicos para desvendar o mundo e corroborar sua teoria, mostrando o quão importante era a química para ele, tendo o poder de explicar o comportamento da natureza.

Em outro experimento do mesmo livro (número Ix), Boyle cita o exemplo da adição de ácido clorídrico em ácido nítrico, mas, agora, em vez de dizer que o material "está se transformando em água régia", ele usa a expressão "virando algo do tipo da água régia", sendo um pouco mais cuidadoso.

Mas eu devo retornar para nossa água régia, porque a menção que eu tive ocasião de fazer daquele solvente trouxe à minha mente o que eu tinha planejado: tornar possível que a pequenez, mais do que alguém jamais poderia imaginar, do volume, da forma ou solidez dos corpúsculos de um mênstruo pode torná-lo apto a dissolver um corpo que não podia anteriormente (...) Pois, apesar de nós não acharmos que nosso espírito do sal aqui na Inglaterra irá de forma alguma dissolver ouro bruto, descobrimos que adicionando algumas folhas de ouro em uma conveniente quantidade de bom espírito do sal, quando gotejamos espírito do nitro (...) a mistura é apta, em um calor moderado, a dissolver o ouro. Nós descobrimos (...) então (...) que a adição de espírito do nitro serviu para transformar o espírito do sal em um tipo de água régia (Boyle, 2000, v. 8, p. 465).

Dessa forma, é difícil concluir se ele acredita que o novo material é realmente água régia, ou se é algum composto novo que também adquiriu essa capacidade, tornando-se como ela. Boyle não é muito claro a respeito disso e não se expressa de modo uniforme ao longo de todo o seu trabalho. Portanto, aparentemente ele está sendo comedido. Considerou certamente que esse novo material tornou-se algo novo com as mesmas propriedades essenciais da água régia (dissolvendo ouro e não prata). Como essa nova capacidade pode definir o corpo como água régia, não estaria errado dizer que esse novo material é, de fato, água régia, pois não existindo aqui nada como uma essência separada, é essa propriedade química que define o corpo.

4. "Dado isso, meu principal objetivo é tornar provável, por meio de experimentos (que eu acredito que ainda não foram feitos), que quase todos os tipos de qualidades, a maioria das quais têm sido deixada pelos escolásticos ou sem explicação ou foram explicadas por meio de incompreensíveis formas substanciais, podem ser produzidas mecanicamente por agentes corporais que não trabalham de outra forma senão em virtude do movimento, tamanho, figura e agrupamento de suas próprias partes (atributos estes que eu chamo de afecções mecânicas da matéria, porque a eles os homens comparam voluntariamente as operações de engenhos mecânicos) (...). Para produzir novas qualidades exibidas por aqueles corpos (...) isso não ocorre por nenhum outro motivo além da alteração de textura ou de movimento ou de alguma outra afecção mecânica dos corpos em questão" (Boyle, 2000, v. 5, p. 3o2). Para uma discussão da filosofia mecânica de Boyle e sua relação com alguns aspectos de sua alquimia, como, por exemplo, os "princípios ativos" da matéria, ver Cecon (2011b, cap. 2). 
A tradução química de experimentos alquímicos envolvendo água régia em Robert Boyle

Boyle é extremamente versátil no uso de suas experiências e utiliza o mesmo experimento para argumentar contra os químicos vulgares (cf. Principe, 1998, cap. 2), que diziam que, nos termos de Boyle e da época, "o espírito do sal estava enfraquecendo a água forte e, por isso, ela não conseguia dissolver mais a prata". Isso não faz sentido algum já que esse novo material é capaz de dissolver até mesmo ouro, um componente muito mais compacto e denso do que a prata, de acordo com os próprios químicos vulgares,

e se você adicionar espírito do sal, ainda que muito forte, em água forte, este líquido não irá dissolver prata porque nessa mistura os líquidos adquirem uma nova constituição (...) motivo pelo qual a mistura irá dissolver, no lugar de prata, ouro. Com isso podemos argumentar contra os químicos que a inabilidade deste líquido composto em agir sobre a prata não procede do fato de que a água forte foi enfraquecida pelo espírito do sal porque, também de acordo com eles, o ouro é um metal muito mais compacto e requer um mênstruo mais potente para agir sobre ele (Boyle, 2000 , v. 8, p. 471).

A inabilidade do ácido nítrico de dissolver a prata, como já havíamos previamente explicado, é devida ao mesmo motivo que o habilita a dissolver o ouro, ou seja, a presença de íons cloreto $\left(\mathrm{Cl}^{-}\right)$. Esses íons juntamente com o ácido nítrico $\left(\mathrm{HNO}_{3}\right)$ podem formar ânions cloroauratos $\left(\left[\mathrm{AuCl}_{4}\right]^{-}\right)$com o ouro, que é solúvel, e também formar cloreto de prata (AgCl) com a prata $(\mathrm{Ag})$, que é insolúvel.

$$
\mathrm{Ag}_{(\mathrm{aq})}^{+}+\mathrm{Cl}_{(\mathrm{aq})}^{-} \rightarrow \mathrm{AgCl}_{(\mathrm{s})}
$$

O mais interessante é que esse material é bem conhecido pelos alquimistas. Boyle, para obtê-lo, primeiro fez a dissolução do material em ácido nítrico e, posteriormente, realizou uma precipitação com ácido clorídrico seguido do isolamento do sal e, então, a secagem e o derretimento em uma massa fundida. Isso gerou o que era então chamado na época de luna cornea. Boyle realizou esse experimento para mostrar que a luna cornea poderia ser obtida dessa maneira. É como se ele estivesse desenvolvendo um processo alternativo para a produção do material, como mostra o trecho abaixo:

tome-se uma boa prata e, dissolvendo-a em água forte, precipite-se a mesma com uma quantidade suficiente de bom espírito do sal. Então, tendo lavado a cal, que será muito branca, com água comum, uma vez muito bem seca, derreta-a com fogo moderado em uma massa fundível, que será muito da mesma natureza do que os químicos chamam de luna cornea (Boyle, 2000, v. 8, p. 478). 
A notação química contemporânea que serviria como chave de leitura para essa descrição seria a seguinte:

$$
\begin{gathered}
\mathrm{Ag}_{(\mathrm{s})}+2 \mathrm{HNO}_{3(\mathrm{aq})} \rightarrow \mathrm{Ag}_{(\mathrm{aq})}^{+}+\mathrm{NO}_{3}^{-}(\mathrm{aq}) \\
\mathrm{Ag}_{(\mathrm{aq})}^{+}+\mathrm{NO}_{2(\mathrm{~g})}+\mathrm{H}_{2} \mathrm{O}_{(\mathrm{lq})} \rightarrow \mathbf{A g C l}_{(\mathrm{s})}+\mathrm{H}_{(\mathrm{aq})}^{+}
\end{gathered}
$$

O trecho citado é uma receita para obter luna cornea, precipitando prata dissolvida com ácido clorídrico. Mais uma vez Boyle parece cuidadoso ao observar que esse material é "muito da mesma natureza" da luna cornea, insinuando que ele possui todas suas propriedades.

\section{Considerações finais}

Boyle realizou junto com os experimentos de água régia uma série de procedimentos químicos, incluindo aqueles relacionados à formação de sais como nitrato de sódio, carbonato de sódio e cloreto de prata, além da produção de materiais em laboratório, como o ácido clorídrico. Aparentemente Boyle estava realmente propondo métodos de obtenção de substâncias ou transmutação de materiais e, na maioria das vezes, e faz isso com o intuito de corroborar sua filosofia corpuscular.

Os exemplos citados neste trabalho mostram como os experimentos boyleanos não são meras técnicas avulsas, pois existe a identificação do que reage com o que e de que forma, de onde vêm esses materiais que reagem entre si e o desenvolvimento de metodologias, visando ou a resolução de problemas, ou o suporte a uma teoria da matéria. É evidente que isso é um conhecimento químico de fato e não pode ser ignorado como parte da história da filosofia da natureza.

O trabalho de tradução para a química contemporânea parece proceder nos casos apresentados neste artigo. Todos os experimentos avaliados parecem ser passíveis de uma tradução química, e não falham na referência. Alguns fatores ajudam como, por exemplo, o cuidado de Boyle em relatar todos os seus experimentos, de forma a serem reproduzidos por uma suposta testemunha virtual, realmente auxiliam a identificação dos reagentes, produtos e reações em geral. As suas anotações são cuidadosamente detalhadas, com boas explicações e descrições dos procedimentos experimentais e também as condições em que o experimento foi realizado, assim como os materiais utilizados.

A tradução química realizada neste artigo, nos experimentos envolvendo água régia, serve como chave de leitura dos materiais e processos descritos de forma tal que facilitam a compreensão, por parte de um químico contemporâneo, daquilo que está ocorrendo nos experimentos em questão. Esse processo, corretamente utilizado e devidamente explicado, pode ser uma valiosa ferramenta para a história da química.@ 
Professor do Departamento de Filosofia, Universidade Estadual Paulista Júlio de Mesquita Filho, Brasil. klebercecon@marilia.unesp.br

\begin{abstract}
Recently some scholars have demonstrated that chemical translation can assist with historical work. The goal of this paper is to translate some of Robert Boyle's alchemical experiments involving aqua regia to contemporary chemistry. Most of them are related to his mechanistic ideas and addresses to routes of productions and for standardization of chemical procedures. Several involve precise descriptions of properties, such as melting point, change of taste, hissing, corrosion, bubbles etc., which may be very useful as tools for chemical translation.
\end{abstract}

KeYwords $\bullet$ Boyle. Alchemical experiments. Chemical translation. Aqua regia. History of chemistry. History of science.

\title{
REFERÊNGIAS BIBLIOGRÁFIGAS
}

Anstey, P. The philosophy of Robert Boyle. London: Routledge, 2000.

Boyle, R. Essay on nitre. In: Hunter, M. \& Davis, E. A. (Ed.). The works of Robert Boyle. London: Pickering and Chatto, 2000. v. 2, p. 93-113.

. History of fluidity and firmness. In: Hunter, M. \& Davis, E. A. (Ed.). The works of Robert Boyle. London: Pickering and Chatto, 2000. v. 2, p. 115-203.

Mechanical origin of qualities. In: Hunter, M. \& DAvis, E. A. (Ed.). The works of Robert Boyle. London:

Pickering and Chatto, 2000. v. 8, p. $315^{-5} 5^{23}$.

The origin of forms and qualities. In: Hunter, M. \& Davis, E. A. (Ed.). The works of Robert Boyle. London: Pickering and Chatto, 2000. v. 5, p. 281-491.

Producibleness of chymical principles. In: Hunter, M. \& Davis, E. A. (Ed.). The works of Robert Boyle. London: Pickering and Chatto, 2000.v. 9, p. 19-120.

. That the goods of mankind. In: Hunter, M. \& Davis, E. A. (Ed.). The works of Robert Boyle. London: Pickering and Chatto, 2000. v. 6, p. 4,65-4, 5 .

.Workdiaries. Edited by Michael Hunter. London: University of London, Centre for Editing Lives and Letters, 1997-2001. Disponível em: 〈http://www.bbk.ac.uk/Boyle/workdiaries/>. Acesso em: o3 set. 2012. (WD)

Canguilhem, G. Études d histoire et de philosophie des sciences. 7. ed. Paris: Vrin, 1979.

Cecon, K. Chemical translation: the case of Robert Boyle's experiments on sensible qualities. Annals of Science, 68, 2, p. 179-98, 2011 .

. A relação entre a filosofia mecânica e os experimentos alquímicos de Robert Boyle. Campinas: UNICAMP, Centro de Lógica, Epistemologia e História da Ciência, 2011b. (Coleção CLE, 61)

Deвus, A. G. Chemists, physicians, and changing perspectives on the scientific revolution. Isis, 89, 1, p. 66-81, 1998.

Goldfarb, A. M. A. Da alquimia à química: um estudo sobre a passagem do pensamento mágico-vitalista ao mecanicismo. São Paulo: Nova Stella: Edusp, 1987. 
Holmes, F. \& Levere, T. H. (Ed.). Instruments and experimentation in the history of chemistry. Cambridge: MIT Press, 2000.

Hunter, M. Robert Boyle by himself and his friends. London: Pickering and Chatto, 1994.

Hunter, M. \& Davis, E. A. (Ed.). The works of Robert Boyle. London: Pickering and Chatto, 2000. 15 v.

Kitcher, P. Theories, theorists and theoretical change. Philosophical Review, 87, 4, p. 519-47, $197^{8}$.

. Implications of incommensurability. Proceedings of the Science Association. Chicago: Chicago University Press, 2, p. 689-7०3, 1982.

Kronвerg, B. I. et al. Mass-spectrometry as a historical probe - quantitative answers to historical questions in metallurgy. Advances in Chemistry Series, 205, p. 295-310, 1984.

Kunn, T. Comensurabilidade, comparabilidade, comunicabilidade. In: ra: ensaios filosóficos, 1970-1993. São Paulo: Ed. UNESP, 2006. p. 47-76.

Newman, W. R. \& Grafton, A. (Ed.). Secrets of nature: astrology and alchemy in early modern Europe. Cambridge: MIT Press, 2001.

Newman, W. R. \& Principe, L. M. Alchemy vs. chemistry: etymological origins of a historiographic mistake. Early Science and Medicine, 3, 1, p, 32-65, 1998.

. Some problems with the historiography of alchemy. In: Newman, W. R. \& Grafton, A. (Ed.). Secrets of nature: astrology and alchemy in early modern Europe. Cambridge: MIT Press, 2001. p. 385-431.

Alchemy tried in the fire: Starkey, Boyle and the fate of Helmontian chymistry. Chicago: University of Chicago Press, 2002.

. (Ed.). George Starkey: alchemical laboratory notebooks and correspondence. Chicago: University of Chicago Press, 2004.

PRINGipe, L. M. Chemical translation and the role of impurities in alchemy: examples from Basil Valentine's triumph-wagen. Ambix, 34, 1, p. 21-30, 1987 .

. Robert Boyle's alchemical secrecy: codes, ciphers, and alchemical concealments. Ambix, 39, 2, p. 63-74, 1992.

. The aspiring adept: Robert Boyle and his alchemical quest. Princeton: Princeton University Press, 1998.

Apparatus and reproducibility in alchemy. In: Holmes, F. \& Levere, T. H. (Ed.). Instruments and experimentation in the history of chemistry. Cambridge: MIT Press, 2000. p. 55-74.

Usselman, M. G. et al. Dalton's disputed nitric oxide experiments and the origins of his atomic theory. European Journal of Chemical Physics and Physical Chemistry, 9, p.106-10, 2008. 